\title{
New Amides and Phenylpropanoid Glucosides from the Fruits of Piper retrofractum
}

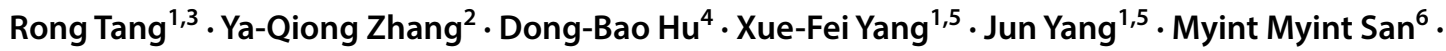 \\ Thaung Naing $\mathrm{Oo}^{6} \cdot \mathrm{Yi} \mathrm{Kong}^{2} \cdot$ Yue-Hu Wang ${ }^{1,5}$
}

Received: 17 March 2019 / Accepted: 21 April 2019 / Published online: 9 May 2019

(C) The Author(s) 2019

\begin{abstract}
Two new amides $(E)$ - $N$-cinnamoyl-2-methoxypiperidine $(\mathbf{1})$ and $(R)$-1-(2-oxopyrrolidin-3-yl)-5,6-dihydropyridin-2(1H)-one (2), four new amide glucosides, retrofractosides A-D (3-6), and two new phenylpropanoid glucosides, retrofractosides E (7) and F (8), together with 24 known compounds (9-32) were isolated from the fruits of Piper retrofractum. The chemical structures of these new compounds were elucidated based on extensive spectroscopic analysis. All of these isolates (1-32) were evaluated for inhibitory activity against mouse platelet aggregation induced by the peptide AYPGKF- $\mathrm{NH}_{2}$. (E)- $\mathrm{N}$-(Tetrahydro-2H-pyran-2-yl)cinnamamide (9) showed a weak inhibitory effect, with an inhibition ratio of $52.0 \%$ at a concentration of $150 \mu \mathrm{M}$.
\end{abstract}

\section{Graphical Abstract}

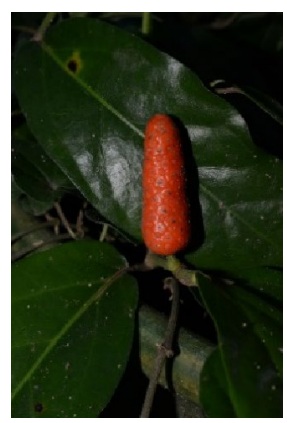<smiles>COCCOc1ccc(/C=C/C(=O)N2CCCCC2)cc1OCCOC</smiles><smiles>O=C(/C=C/c1ccccc1)NC1CCCCO1</smiles>
cinnamamide (9)

Keywords Piper retrofractum $\cdot$ Piperaceae $\cdot$ Antiplatelet $\cdot$ Amides $\cdot$ Phenylpropanoids

Rong Tang and Ya-Qiong Zhang contributed equally to this work.

Electronic supplementary material The online version of this article (https://doi.org/10.1007/s13659-019-0208-z) contains supplementary material, which is available to authorized users.

Yi Kong

yikong668@163.com

Yue-Hu Wang

wangyuehu@mail.kib.ac.cn

Extended author information available on the last page of the article

\section{Introduction}

Piper retrofractum Vahl (Piperaceae) is primarily distributed in Southeast Asia and cultivated in Indonesia and Thailand [1]. The fruits of this plant have been used in folk medicine to treat asthma, bronchitis, dyspepsia, and sleep problems in Southeast Asia [2]. The major constituents of $P$. retrofractum are amides [3-6]. Several amides from the plant exhibit significant biological activities, such as antifungal [5], insecticidal [7], hepatoprotective [8], and gastroprotective activities [9]. Piper plants are rich in amides, lignans, and phenylpropanoids with antiplatelet aggregation activities. More than 50 antiplatelet compounds have been found 
from this genus [10-13]. In a continuing effort to search for antiplatelet compounds from Piper plants [11-13], the fruits of $P$. retrofractum were phytochemically studied, which led to the isolation of eight new compounds (1-8, Fig. 1). The structural elucidation of these new compounds and the results of the antiplatelet bioassays are reported here.

\section{Results and Discussion}

\subsection{Structure Elucidation}

Compound 1 was obtained as a white amorphous powder. Its molecular formula was determined to be $\mathrm{C}_{15} \mathrm{H}_{19} \mathrm{NO}_{2}$ by ${ }^{13} \mathrm{C}$
NMR data (Table 1) and HREIMS, which revealed a molecular ion peak at $m / z 245.1423[\mathrm{M}]^{+}\left(\right.$calcd for $\mathrm{C}_{15} \mathrm{H}_{19} \mathrm{NO}_{2}$, 245.1416), which implies seven degrees of unsaturation.

The ${ }^{1} \mathrm{H}$ NMR and ${ }^{13} \mathrm{C}$ NMR data (Table 1) indicated the presence of an (E)-cinnamoyl moiety and a 2-methoxypiperidine moiety, as demonstrated by comparing the NMR data with those from $(E)$ - $N$-(tetrahydro- $2 \mathrm{H}$ pyran-2-yl)cinnamamide (9) and $N$-benzyloxycarbonyl-2methoxypiperidine [14]. The double bond was deduced to be an $E$ configuration from the coupling constant between $\mathrm{H}^{-7}{ }^{\prime}$ and $\mathrm{H}-8^{\prime}\left(J_{7^{\prime}, 8^{\prime}}=15.4 \mathrm{~Hz}\right)$. Based on the HMBC correlations from OMe to $\mathrm{C}-2$ (Fig. 2), the methoxy group was located at $\mathrm{C}-2$. The $(E)$-cinnamoyl and 2-methoxypiperidine moieties were confirmed by the COSY and HMBC correlations<smiles>COC1CCCCN1C(=O)/C=C/c1ccccc1</smiles><smiles>CC/C=C/c1ccc(OC2O[C@H](CO)[C@@H](O)[C@H](O)[C@H]2O)c(O[C@@H]2OC(CO)[C@@H](O)[C@H](O)[C@H]2O)c1</smiles><smiles>O=C1NCCC1N1CCC=CC1=O</smiles><smiles>C1CCC1</smiles><smiles>CN1CCCCC1</smiles><smiles>OC[C@H]1O[C][C](O)[C@@H](O)[C@@H]1O</smiles><smiles>CC(CO)Oc1cc(/C=C\C(=O)N2CCCCC2)ccc1OC1O[C@H](CO)[C@@H](O)C(C)[C@H]1O</smiles><smiles></smiles><smiles>CC(C)[C@H](CO)O[C@H]1O[C@H](CO)[C@@H](O)[C@H](O)[C@H]1O</smiles>
$\mathrm{HO}$ $\mathrm{OH}$

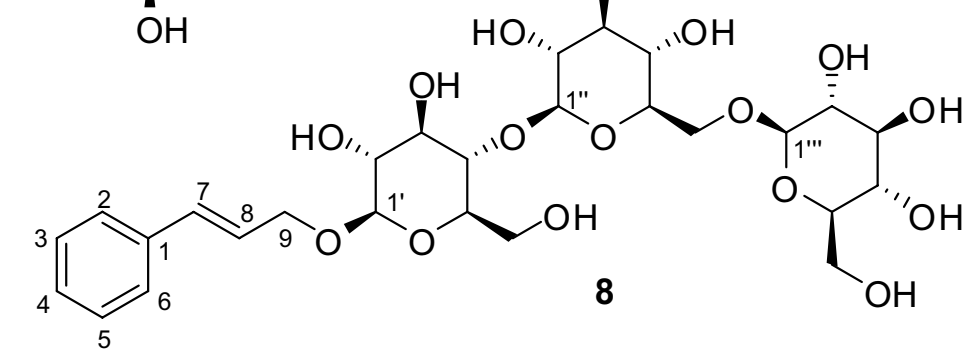

Fig. 1 Chemical structures of new compounds (1-8) from Piper retrofractum 
Table $1{ }^{1} \mathrm{H}(800 \mathrm{MHz})$ and ${ }^{13} \mathrm{C}$ NMR $(201 \mathrm{MHz})$ data of $\mathbf{1}$ in $\mathrm{CDCl}_{3}$

\begin{tabular}{lll}
\hline No. & $\delta_{\mathrm{H}}(\mathrm{J}, \mathrm{Hz})$ & $\delta_{\mathrm{C}}$ \\
\hline 2 & $5.91(\mathrm{br} \mathrm{s})$ & 79.9 \\
& $5.28(\mathrm{br} \mathrm{s})$ & 83.9 \\
3 & $1.98(\mathrm{br} \mathrm{d}, 12.0), 1.63(\mathrm{~m})$ & 31.2 \\
& $1.94(\mathrm{br} \mathrm{d}, 13.3), 1.61(\mathrm{~m})$ & 30.2 \\
4 & $1.85(2 \mathrm{H}, \mathrm{m}), 1.61(2 \mathrm{H}, \mathrm{m})$ & 18.9 \\
5 & $1.73(\mathrm{~m}), 1.51(\mathrm{~m})$ & 26.2 \\
& $1.73(\mathrm{~m}), 1.50(\mathrm{~m})$ & 25.1 \\
6 & $4.49(\mathrm{br} \mathrm{d}, 12.3), 2.88(\mathrm{br} \mathrm{t}, 12.3)$ & 37.1 \\
& $3.82(\mathrm{br} \mathrm{d}, 12.6), 3.34(\mathrm{br} \mathrm{t}, 12.6)$ & 41.1 \\
$1^{\prime}$ & & 135.4 \\
$2^{\prime}, 6^{\prime}$ & $7.53(2 \mathrm{H}, \mathrm{br} \mathrm{d}, 7.5), 7.52(2 \mathrm{H}, \mathrm{br} \mathrm{d}, 7.5)$ & $127.94,127.88$ \\
$3^{\prime}, 5^{\prime}$ & $7.38(4 \mathrm{H}, \mathrm{m})$ & 129.0 \\
$4^{\prime}$ & $7.36(2 \mathrm{H}, \mathrm{m})$ & 129.8 \\
$7^{\prime}$ & $7.69(\mathrm{~d}, 15.4), 7.68(\mathrm{~d}, 15.4)$ & $143.4,143.1$ \\
$8^{\prime}$ & $6.91(\mathrm{~d}, 15.4), 6.90(\mathrm{~d}, 15.4)$ & 117.7 \\
$9^{\prime}$ & & $166.7,166.5$ \\
$2-\mathrm{OMe}$ & $3.28(3 \mathrm{H}, \mathrm{s})$ & 55.1 \\
& $3.25(3 \mathrm{H}, \mathrm{s})$ & 54.4 \\
\hline
\end{tabular}

(Fig. 2). Although correlations from $\mathrm{H}-2$ to $\mathrm{C}-9^{\prime}$ and $\mathrm{H}_{2}-6$ to C-9' were not observed in the HMBC spectrum, based on the molecular formula of $\mathbf{1}$ that was deduced from its HREIMS spectrum as well as the chemical shift of C-9' indicating an amide carbonyl group, it can be concluded that these two fragments are connected through an amide bond. The ROESY correlations of $\mathrm{H}-2 / \mathrm{H}-8^{\prime}$ and $\mathrm{H}-6 / \mathrm{H}-8^{\prime}$ (Fig. 2) also support the deduction. Therefore, the planar structure of $\mathbf{1}$ was elucidated to be (E)- $N$-cinnamoyl-2-methoxypiperidine. It is noteworthy that NMR signals for the two rotational isomers of 1 were observed due to the hindered rotation about the amide bond [15]. No Cotton effects were observed in the ECD spectrum (data not shown). Because the compound was used up in the bioassay, the chiral analysis was not conducted. The absolute configuration of $\mathbf{1}$ remained unknown.

Compound 2 was obtained as a white amorphous powder. Its molecular formula was determined to be $\mathrm{C}_{9} \mathrm{H}_{12} \mathrm{~N}_{2} \mathrm{O}_{2}$ by ${ }^{13} \mathrm{C}$ NMR data and HRESIMS. The ${ }^{1} \mathrm{H}$ NMR spectrum exhibited signals for a disubstituted double bond at $\delta_{\mathrm{H}} 6.76$ (dt, $J=9.8,4.2 \mathrm{~Hz}$ ) and $5.87(\mathrm{dt}, J=9.8,1.8 \mathrm{~Hz}$ ). The ${ }^{13} \mathrm{C}$ NMR spectrum indicated the presence of two carbonyl groups, one each at $\delta_{\mathrm{C}} 180.7$ and 166.6. Comparison of the ${ }^{1} \mathrm{H}$ NMR and ${ }^{13} \mathrm{C}$ NMR data of 2 with those of 5,6-dihydro$1 H$-pyridin-2-one (22) confirmed the presence of a 5,6-dihydro- $1 H$-pyridin-2-one moiety [16]. The remaining fragment was deduced to be 3-amino-2-oxopyrrolidine, based on the COSY correlations of $\mathrm{H}-3^{\prime} / \mathrm{H}_{2}-4^{\prime}$ and $\mathrm{H}_{2}-4^{\prime}$ ' $\mathrm{H}_{2}-5^{\prime}$ and the $\mathrm{HMBC}$ correlations from $\mathrm{H}_{2}-5^{\prime}$ to $\mathrm{C}-2^{\prime}$ and from $\mathrm{H}_{2}-4^{\prime}$ to $\mathrm{C}-2^{\prime}$ (Fig. 2). These two fragments were found to be connected through a carbon-nitrogen bond based on the HMBC correlations from $\mathrm{H}-3$ ' to C-2 and C- 6 and from $\mathrm{H}_{2}-6$ to $\mathrm{C}-3^{\prime}$. Thus, the structure of $\mathbf{2}$ was determined to be 1-(2-oxopyrrolidin-3-yl)-5,6-dihydropyridin-2(1H)-one. Several very weak Cotton effects were observed in the ECD spectrum of 2 . At the same time, it was found to have a negative value of optical rotation $\left([\alpha]_{\mathrm{D}}^{20}-15.6(c=0.23\right.$, $\mathrm{MeOH})$ ). When compound 2 was analyzed by HPLC using a chiral CD-Ph column, only one peak was observed. The chemical calculations of ECD and optical rotation were conducted. Although the Cotton effects were not strong, the calculated ECD spectrum for $(R)-2$ was mostly consistent with the experimental ECD spectrum for ( - )-2 (Fig. 3). The calculated value of optical rotation for $(R)-2$ was negative $(-60)$. Therefore, the absolute configuration of $\mathbf{2}$ was suggested to be $R$.

Based on ${ }^{13} \mathrm{C}$ NMR data (Table 2) and the HRESIMS ion peak at $m / z 594.2160[\mathrm{M}+\mathrm{Na}]^{+}\left(\right.$calcd for $\mathrm{C}_{26} \mathrm{H}_{37} \mathrm{NNaO}_{13}$, 594.2163), the molecular formula of retrofractoside $\mathrm{A}(\mathbf{3})$ was deduced to be $\mathrm{C}_{26} \mathrm{H}_{37} \mathrm{NO}_{13}$ with nine degrees of unsaturation. The ${ }^{1} \mathrm{H}$ and ${ }^{13} \mathrm{C}$ NMR data (Table 2) indicated the presence of two $\beta$-glucopyranosyl groups $\left[\delta_{\mathrm{H}} 4.92(\mathrm{~d}, J=\right.$ $7.5 \mathrm{~Hz})$ and $4.91(\mathrm{~d}, J=7.6 \mathrm{~Hz})]$, one $E$-double bond $\left[\delta_{\mathrm{H}}\right.$ $7.48(\mathrm{~d}, J=15.5 \mathrm{~Hz})$ and $7.05(\mathrm{~d}, J=15.5 \mathrm{~Hz})]$, one trisubstituted phenyl ring $\left[\delta_{\mathrm{H}} 7.58(\mathrm{~s})\right.$ and $7.26(2 \mathrm{H}$, overlapped $\left.)\right]$, and one carbonyl group $\left(\delta_{\mathrm{C}} 167.8\right)$. By comparing the NMR data with those of $(E)$-3-phenyl-1-(piperidin-1-yl)prop-2-en1-one (17) and (E)-3-(3,4-dihydroxyphenyl)-1-(piperidin1-yl)prop-2-en-1-one $[17,18]$, an $(E)$ - $N$-caffeoylpiperidine moiety was confirmed, which was supported by the COSY correlations indicating the connection from C-2 to C-6, as well as the HMBC correlations from $\mathrm{H}_{2}-2$ to $\mathrm{C}-6$ and $\mathrm{C}-9^{\prime}$, from $\mathrm{H}-7^{\prime}$ to $\mathrm{C}-2^{\prime}$, C-6', and $\mathrm{C}-9^{\prime}$, and from $\mathrm{H}-8^{\prime}$ to $\mathrm{C}-1^{\prime}$ (Fig. 2). The HMBC correlations (Fig. 2) from $\mathrm{H}-1^{\prime \prime}$ to $\mathrm{C}-3^{\prime}$ and from $\mathrm{H}-1^{\prime \prime \prime}$ to $\mathrm{C}-4$ ' suggested that one glucose unit was linked at $\mathrm{C}-3^{\prime}$, while another unit was linked at C-4'. The configuration of glucose in the plant was determined to be the D-configuration by acidic hydrolysis of piperchabaoside A (30) to yield a D-glucopyranose. Therefore, the structure of retrofractoside A (3) was elucidated to be (E)- $N$-(3,4-di$O-\beta$-D-glucopyranosyl) caffeoylpiperidine.

Retrofractoside B (4) was found to have the same molecular formula, $\mathrm{C}_{26} \mathrm{H}_{37} \mathrm{NO}_{13}$, as that of $\mathbf{3}$, based on ${ }^{13} \mathrm{C}$ NMR data (Table 2) and HRESIMS. The ${ }^{1} \mathrm{H}$ and ${ }^{13} \mathrm{C}$ NMR data (Table 2) of $\mathbf{4}$ also indicated the presence of two $\beta$-glucopyranosyl groups $\left[\delta_{\mathrm{H}} 4.88\right.$ (overlapped, $J_{1^{\prime \prime \prime}, 2^{\prime \prime \prime}}=7.4 \mathrm{~Hz}$ from $\left.\mathrm{H}-2^{\prime \prime \prime}\right)$ and $\left.4.81(\mathrm{~d}, J=7.6 \mathrm{~Hz})\right]$, one trisubstituted phenyl ring $\left[\delta_{\mathrm{H}} 7.33(\mathrm{~d}, J=2.1 \mathrm{~Hz}), 7.22(\mathrm{~d}, J\right.$ $=8.5 \mathrm{~Hz})$, and $7.05(\mathrm{dd}, J=8.5,2.1 \mathrm{~Hz})]$, and one carbonyl group $\left(\delta_{\mathrm{C}} 169.7\right)$. However, the double bond in 4 possessed a $Z$-configuration $\left[\delta_{\mathrm{H}} 6.65(\mathrm{~d}, J=12.5 \mathrm{~Hz})\right.$ and $6.03(\mathrm{~d}, J=$ $12.5 \mathrm{~Hz})]$ rather than an $E$-configuration. Based on the COSY and HMBC correlations (Fig. 2), a (Z)- $N$-caffeoylpiperidine 


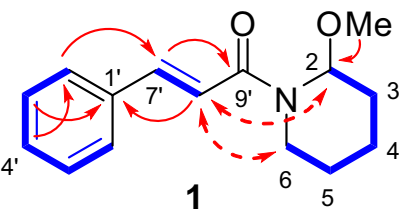

$\mathrm{Me}$

\section{(1)}

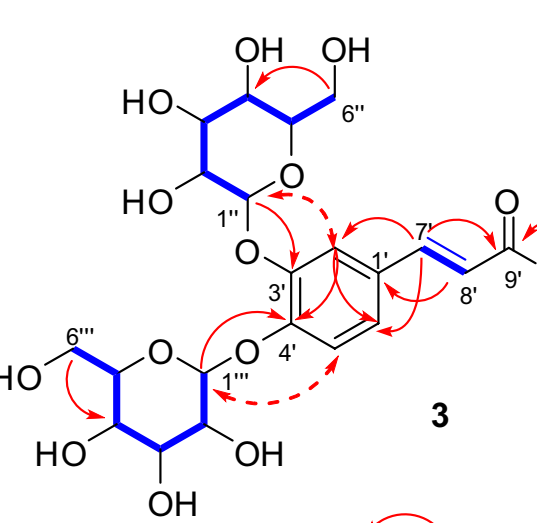
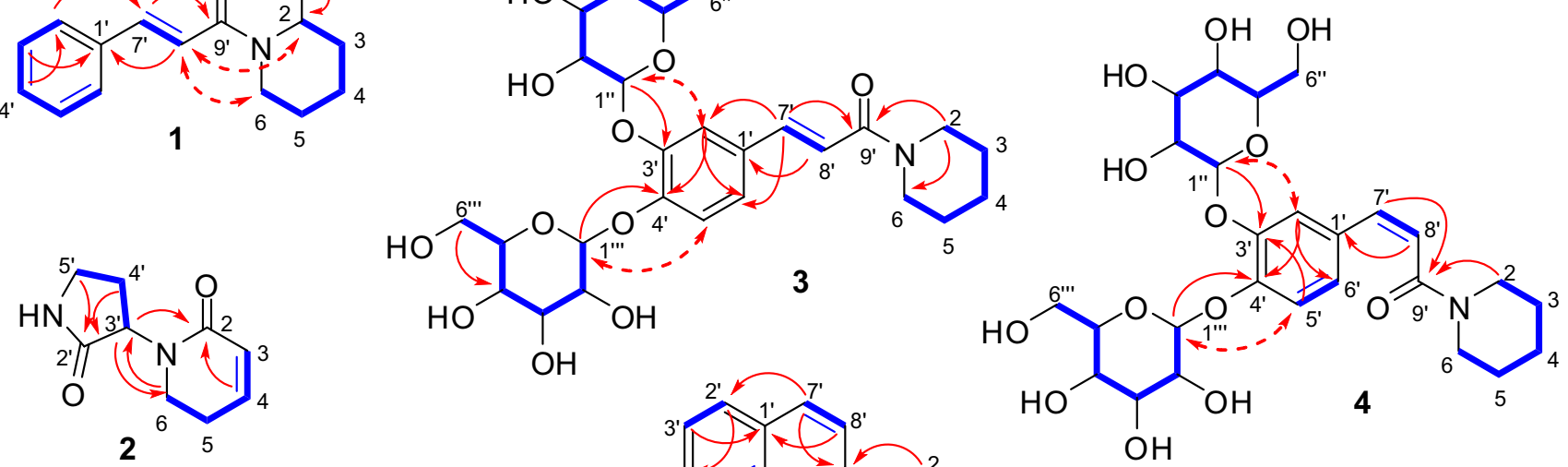

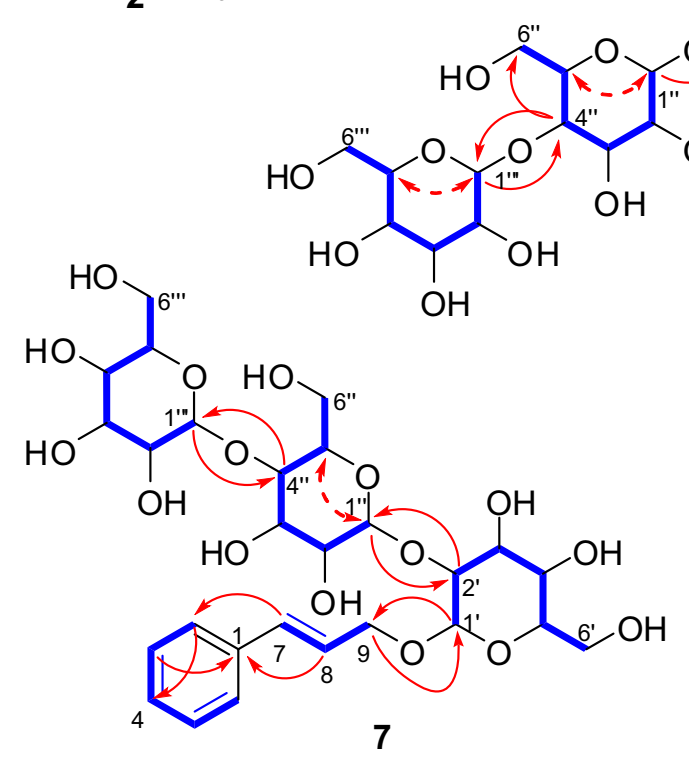<smiles>CC=CCC(C)(C)N1CCCCC1</smiles>

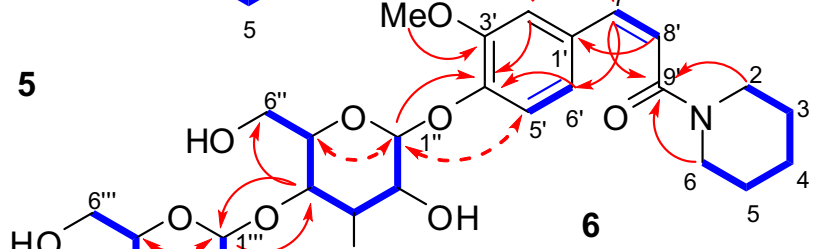<smiles>CC1CC(C)C2(CO)OCC1(CO)CCC2CO</smiles><smiles>OCC(O)C(O)C(O)O</smiles>

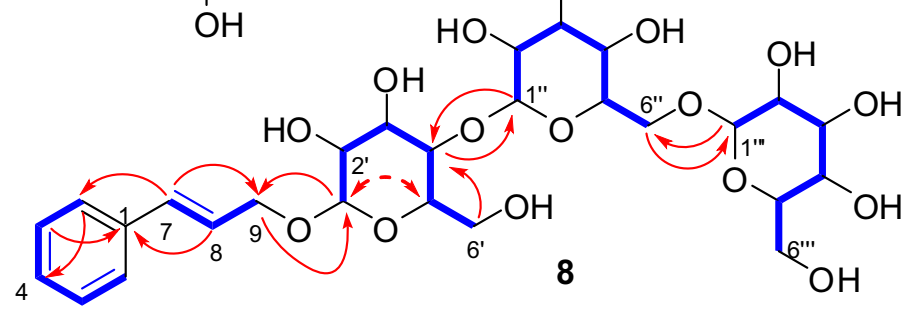

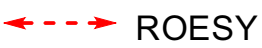

Fig. 2 Key 2D NMR correlations of compounds 1-8

moiety in $\mathbf{4}$ was confirmed. The HMBC correlations (Fig. 2) from $\mathrm{H}-1^{\prime \prime}$ to $\mathrm{C}-3^{\prime}$ and from $\mathrm{H}-1^{\prime \prime}$ ' to $\mathrm{C}-4^{\prime}$ suggested the two sugars were located at $\mathrm{C}-3^{\prime}$ and $\mathrm{C}-4^{\prime}$, respectively. Thus, the structure of retrofractoside B (4) was determined to be (Z)$N$-(3,4-di- $O$ - $\beta$-D-glucopyranosyl) caffeoylpiperidine.

The molecular formula of retrofractoside $\mathrm{C}(\mathbf{5})$ was determined to be $\mathrm{C}_{26} \mathrm{H}_{37} \mathrm{NO}_{12}$, based on the ${ }^{13} \mathrm{C}$ NMR data (Table 3) and the HRESIMS ion peak at $m / z 578.2206$ [M $+\mathrm{Na}]^{+}$(calcd for $\mathrm{C}_{26} \mathrm{H}_{37} \mathrm{NNaO}_{12}, 578.2214$ ). The ${ }^{1} \mathrm{H}$ and ${ }^{13} \mathrm{C}$ NMR data of $\mathbf{5}$ (Table 3) indicated the presence of two $\beta$-glucopyranosyl groups $\left[\delta_{\mathrm{H}} 4.96(\mathrm{~d}, J=7.8 \mathrm{~Hz})\right.$ and 4.43 $(\mathrm{d}, J=7.9 \mathrm{~Hz})]$, a $p$-disubstituted phenyl ring $\left[\delta_{\mathrm{H}} 7.31\right.$ $(2 \mathrm{H}$, br d, $J=8.7 \mathrm{~Hz})$ and $7.07(2 \mathrm{H}$, br d, $J=8.7 \mathrm{~Hz})]$, a $Z$-double bond $\left[\delta_{\mathrm{H}} 6.64(\mathrm{~d}, J=12.6 \mathrm{~Hz})\right.$ and $5.97(\mathrm{~d}, J=$ $12.6 \mathrm{~Hz})]$, and a carbonyl group $\left[\delta_{\mathrm{C}} 169.8\right]$. By comparing its NMR data with those of $\mathbf{3}$ and $\mathbf{4}$, the amide moiety of $\mathbf{5}$ was deduced to be (Z)-N-p-coumaroylpiperidine, which was supported by the COSY and HMBC correlations (Fig. 2). The linkage of the sugars and genin was determined to be Glc- $(1 \rightarrow 4)-G l c-O-C-4$ ' based on the HMBC correlations from $\mathrm{H}-1^{\prime \prime \prime}$ to $\mathrm{C}-4$ ", from $\mathrm{H}-1$ " to $\mathrm{C}-4$ ', from $\mathrm{H}-4$ " to C-6" and $\mathrm{C}-1^{\prime \prime \prime}$ as well as the ROESY correlations of $\mathrm{H}-1{ }^{\prime \prime} / \mathrm{H}-5^{\prime \prime}$ and the COSY correlations of H-5"/H-6" (Fig. 2). Therefore, retrofractoside $\mathrm{C}(\mathbf{5})$ was determined to be $(Z)-N-p$ coumaroylpiperidine 4 '- $O$ - $\beta$-D-glucopyranosyl- $(1 \rightarrow$ 4)- $\beta$-D-glucopyranoside.

Retrofractoside D (6) was found to have the molecular formula, $\mathrm{C}_{27} \mathrm{H}_{39} \mathrm{NO}_{13}$, based on ${ }^{13} \mathrm{C}$ NMR data (Table 3) and HRESIMS. The ${ }^{1} \mathrm{H}$ and ${ }^{13} \mathrm{C}$ NMR data (Table 3) of 6 indicated the presence of two $\beta$-glucopyranosyl groups 


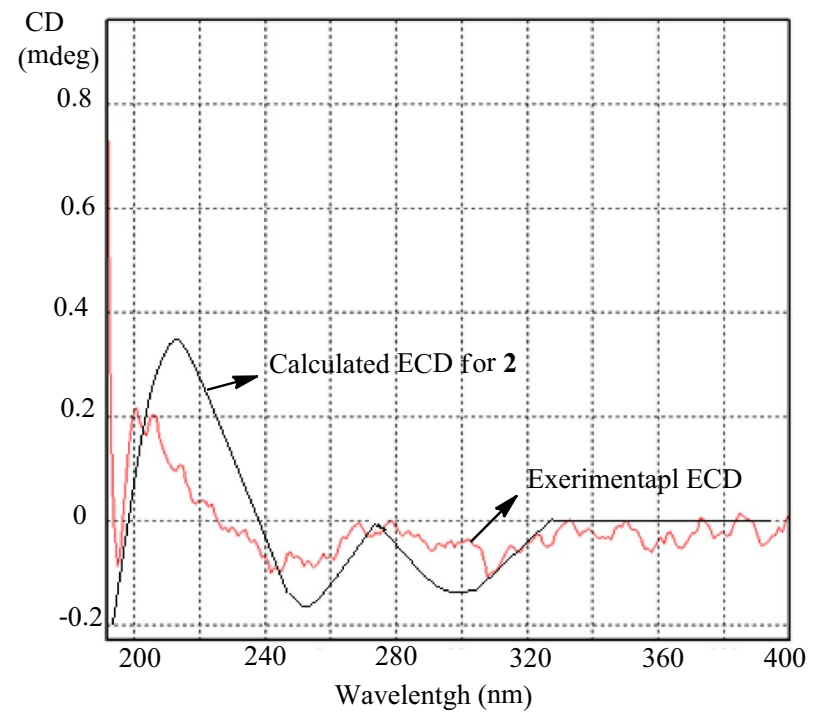

Fig. 3 Experimental and calculated ECD spectra for compound 2

$\left[\delta_{\mathrm{H}} 4.96(\mathrm{~d}, J=7.7 \mathrm{~Hz})\right.$ and $\left.4.44(\mathrm{~d}, J=7.9 \mathrm{~Hz})\right]$, one 1,2,4-trisubstituted phenyl ring $\left[\delta_{\mathrm{H}} 7.11(\mathrm{~d}, J=8.4 \mathrm{~Hz})\right.$, $7.05(\mathrm{~d}, J=1.8 \mathrm{~Hz})$, and $6.92(\mathrm{dd}, J=8.4,1.8 \mathrm{~Hz})]$, one $Z$-double bond $\left[\delta_{\mathrm{H}} 6.64(\mathrm{~d}, J=12.6 \mathrm{~Hz})\right.$ and $6.00(\mathrm{~d}, J=$ $12.6 \mathrm{~Hz})]$, a carbonyl group $\left[\delta_{\mathrm{C}} 169.8\right]$, and a methoxy group $\left[\delta_{\mathrm{H}} 3.82(3 \mathrm{H}, \mathrm{s}) ; \delta_{\mathrm{C}} 56.7\right]$. Based on the HMBC correlations from OMe to C-3' (Fig. 2), the methoxy group was located at C-3'. The amide moiety of 6 was deduced to be (Z)- $N$ feruloylpiperidine from the COSY and HMBC correlations (Fig. 2). The linkage of the sugars and genin in $\mathbf{6}$ was found to be the same mode, Glc- $(1 \rightarrow 4)-$ Glc-O-C-4', as that in 5, based on the HMBC correlations from $\mathrm{H}-1^{\prime \prime \prime}$ to C-4", from $\mathrm{H}-1$ " to C-4', and from $\mathrm{H}-4$ " to C-6" and C-1"' as well as the ROESY correlations of $\mathrm{H}-1{ }^{\prime \prime} / \mathrm{H}-5^{\prime \prime}$ and the COSY correlations H-5"/H-6" (Fig. 2). Accordingly, retrofractoside $\mathrm{D}$ (6) was determined to be (Z)- $N$-feruloylpiperidine $4^{\prime}-O-\beta$ D-glucopyranosyl-( $1 \rightarrow 4)-\beta$-D-glucopyranoside.

Based on ${ }^{13} \mathrm{C}$ NMR (Table 4) and HRESIMS data, the retrofractosides $\mathrm{E}(\mathbf{7})$ and $\mathrm{F}(\mathbf{8})$ were determined to have the same molecular formula, $\mathrm{C}_{27} \mathrm{H}_{40} \mathrm{O}_{16}$. The ${ }^{1} \mathrm{H}$ and ${ }^{13} \mathrm{C}$ NMR data (Table 4) of $\mathbf{7}$ and $\mathbf{8}$ indicated the presence of three $\beta$-glucopyranosyl groups $\left[\delta_{\mathrm{H}} 4.66(\mathrm{~d}, J=7.9 \mathrm{~Hz}), 4.51\right.$ $(\mathrm{d}, J=7.8 \mathrm{~Hz})$, and $4.39(\mathrm{~d}, J=7.9 \mathrm{~Hz})$ in $7 ; \delta_{\mathrm{H}} 4.40(\mathrm{~d}$, $J=7.9 \mathrm{~Hz}), 4.38(\mathrm{~d}, J=7.9 \mathrm{~Hz})$, and $4.31(\mathrm{~d}, J=7.7 \mathrm{~Hz})$ in 8] and an (E)-cinnamyl alcohol moiety $\left[\delta_{\mathrm{H}} 6.69\right.$ (br d, $J=16.0 \mathrm{~Hz})$ and $6.37(\mathrm{dt}, J=16.0,5.9 \mathrm{~Hz})$ in $7 ; \delta_{\mathrm{H}} 6.68$ (br d, $J=16.0 \mathrm{~Hz}$ ) and $6.36(\mathrm{dt}, J=16.0,6.0 \mathrm{~Hz}$ ) in 8] in these two compounds, which could derive from rozin (29) [19] or piperchabaoside A (30) [20]. The sugar chain of 7 was elucidated to be Glc- $(1 \rightarrow 4)$-Glc- $(1 \rightarrow 2)$-Glc based on the HMBC correlations from $\mathrm{H}-1^{\prime \prime \prime}$ to $\mathrm{C}-4^{\prime \prime}$, from $\mathrm{H}-4^{\prime \prime}$ to $\mathrm{C}-1^{\prime \prime \prime}$, from $\mathrm{H}-1^{\prime \prime}$ to $\mathrm{C}-2^{\prime}$, and from $\mathrm{H}-2^{\prime}$ to $\mathrm{C}-1^{\prime \prime}$ as
Table $2{ }^{1} \mathrm{H}(600 \mathrm{MHz})$ and ${ }^{13} \mathrm{C}$ NMR $(151 \mathrm{MHz})$ data of 3 and 4 in methanol- $d_{4}$

\begin{tabular}{|c|c|c|c|c|}
\hline \multirow[t]{2}{*}{ No. } & \multicolumn{2}{|l|}{3} & \multicolumn{2}{|l|}{4} \\
\hline & $\delta_{\mathrm{H}}(J, \mathrm{~Hz})$ & $\delta_{\mathrm{C}}$ & $\delta_{\mathrm{H}}(J, \mathrm{~Hz})$ & $\delta_{\mathrm{C}}$ \\
\hline 2 & $3.69(2 \mathrm{H}, \mathrm{m})$ & 48.4 & $\begin{array}{l}3.43(\mathrm{~m}) \\
3.39(\mathrm{~m})\end{array}$ & 48.8 \\
\hline 3 & $1.64(2 \mathrm{H}, \mathrm{m})$ & 28.1 & $1.29(2 \mathrm{H}, \mathrm{m})$ & 27.3 \\
\hline 4 & $1.72(2 \mathrm{H}, \mathrm{m})$ & 25.7 & $1.57(2 \mathrm{H}, \mathrm{m})$ & 26.6 \\
\hline 5 & $1.60(2 \mathrm{H}, \mathrm{m})$ & 27.1 & $1.59(2 \mathrm{H}, \mathrm{m})$ & 25.5 \\
\hline 6 & $3.65(2 \mathrm{H}, \mathrm{m})$ & 44.8 & $\begin{array}{l}3.67(\mathrm{~m}) \\
3.56(\mathrm{~m})\end{array}$ & 43.6 \\
\hline $1^{\prime}$ & & 132.4 & & 132.7 \\
\hline $2^{\prime}$ & 7.59 (br s) & 119.4 & $7.33(\mathrm{~d}, 2.1)$ & 121.0 \\
\hline $3^{\prime}$ & & 149.5 & & 149.0 \\
\hline $4^{\prime}$ & & 150.7 & & 149.7 \\
\hline $5^{\prime}$ & 7.26 (overlapped) & 120.2 & $7.22(\mathrm{~d}, 8.5)$ & 120.3 \\
\hline $6^{\prime}$ & 7.26 (overlapped) & 125.7 & $7.05(\mathrm{dd}, 8.5,2.1)$ & 125.6 \\
\hline $7^{\prime}$ & $7.48(\mathrm{~d}, 15.5)$ & 143.3 & $6.65(\mathrm{~d}, 12.5)$ & 134.1 \\
\hline $8^{\prime}$ & $7.05(\mathrm{~d}, 15.5)$ & 118.0 & $6.03(\mathrm{~d}, 12.5)$ & 123.5 \\
\hline $9^{\prime}$ & & 167.8 & & 169.7 \\
\hline $1^{\prime \prime}$ & $4.91(\mathrm{~d}, 7.6)$ & 104.2 & $4.81(\mathrm{~d}, 7.6)$ & 104.2 \\
\hline $2^{\prime \prime}$ & $3.52(\mathrm{~m})$ & 75.3 & $3.49(\mathrm{~m})$ & 75.2 \\
\hline $3^{\prime \prime}$ & $3.47(\mathrm{~m})$ & 78.0 & $3.45(\mathrm{~m})$ & 78.0 \\
\hline $4^{\prime \prime}$ & $3.37(\mathrm{dd}, 9.7,8.8)$ & 71.7 & $3.40(\mathrm{~m})$ & 71.4 \\
\hline $5^{\prime \prime}$ & $3.41(\mathrm{~m})$ & 78.6 & $3.37(\mathrm{~m})$ & 78.5 \\
\hline $6^{\prime \prime}$ & $\begin{array}{l}3.88(\mathrm{~m}) \\
3.69(\mathrm{~m})\end{array}$ & 62.7 & $\begin{array}{l}3.90(\mathrm{dd}, 12.0,2.2) \\
3.70(\mathrm{~m})\end{array}$ & 62.6 \\
\hline $1^{\prime \prime \prime}$ & $4.92(\mathrm{~d}, 7.5)$ & 103.7 & 4.88 (overlapped) & 103.8 \\
\hline $2^{\prime \prime \prime}$ & $3.52(\mathrm{~m})$ & 75.1 & $3.50(\mathrm{dd}, 9.2,7.4)$ & 75.1 \\
\hline $3^{\prime \prime \prime}$ & $3.47(\mathrm{~m})$ & 77.9 & $3.45(\mathrm{~m})$ & 77.9 \\
\hline $4^{\prime \prime \prime}$ & $3.40(\mathrm{~m})$ & 71.4 & $3.40(\mathrm{~m})$ & 71.4 \\
\hline $5^{\prime \prime \prime}$ & $3.41(\mathrm{~m})$ & 78.5 & $3.37(\mathrm{~m})$ & 78.4 \\
\hline $6^{\prime \prime \prime}$ & $\begin{array}{l}3.88(\mathrm{~m}) \\
3.69(\mathrm{~m})\end{array}$ & 62.6 & $\begin{array}{l}3.86(\mathrm{dd}, 12.1,2.0) \\
3.73(\mathrm{dd}, 12.1,5.2)\end{array}$ & 62.5 \\
\hline
\end{tabular}

well as the COSY correlations of $\mathrm{H}-1^{\prime} / \mathrm{H}-2^{\prime}$ and $\mathrm{H}-4^{\prime \prime} / \mathrm{H}-5^{\prime \prime}$ and the ROESY correlations of $\mathrm{H}-1{ }^{\prime \prime} / \mathrm{H}-5^{\prime \prime}$. According to the HMBC correlations from $\mathrm{H}-1^{\prime \prime \prime}$ to $\mathrm{C}-6^{\prime \prime}$, from $\mathrm{H}_{2}-6^{\prime \prime}$ to $\mathrm{C}-1^{\prime \prime \prime}$, from $\mathrm{H}-1^{\prime \prime}$ to $\mathrm{C}-4^{\prime}$, from $\mathrm{H}-4^{\prime}$ to $\mathrm{C}-1^{\prime \prime}$, and from $\mathrm{H}-6^{\prime} \mathrm{a}$ to $\mathrm{C}-4^{\prime}$ as well as the COSY correlations of $\mathrm{H}-4^{\prime} / \mathrm{H}-5^{\prime}$ and $\mathrm{H}-5^{\prime} / \mathrm{H}_{2}-6^{\prime}$ and the ROESY correlations of $\mathrm{H}-1^{\prime} / \mathrm{H}-5^{\prime}$, the sugar chain of 8 was deduced to be Glc- $(1 \rightarrow 6)$-Glc- $(1 \rightarrow$ 4)-Glc. The sugar chains of both compounds were found to be attached to the C-9 position of aglycone, based on the $\mathrm{HMBC}$ correlations from $\mathrm{H}-1^{\prime}$ to $\mathrm{C}-9$ and from $\mathrm{H}_{2}-9$ to $\mathrm{C}-1^{\prime}$. Therefore, the structures of retrofractosides $\mathrm{E}$ (7) and $\mathrm{F}(\mathbf{8})$ were determined to be $(E)$-cinnamyl alcohol 9- $O$ - $\beta$-D-glucopyranosyl-( $1 \rightarrow 4)-\beta$-D-glucopyranosyl- $(1 \rightarrow$ $2)$ - $\beta$-D-glucopyranoside and (E)-cinnamyl alcohol $9-O-\beta$-Dglucopyranosyl-( $1 \rightarrow 6)$ - $\beta$-D-glucopyranosyl- $(1 \rightarrow 4)$ - $\beta$-Dglucopyranoside, respectively. 
Table $3{ }^{1} \mathrm{H}(800 \mathrm{MHz})$ and ${ }^{13} \mathrm{C}$ NMR $(201 \mathrm{MHz})$ data of 5 and $\mathbf{6}$ in methanol- $d_{4}$

\begin{tabular}{|c|c|c|c|c|}
\hline \multirow[t]{2}{*}{ No. } & \multicolumn{2}{|l|}{5} & \multicolumn{2}{|l|}{6} \\
\hline & $\delta_{\mathrm{H}}(J, \mathrm{~Hz})$ & $\delta_{\mathrm{C}}$ & $\delta_{\mathrm{H}}(J, \mathrm{~Hz})$ & $\delta_{\mathrm{C}}$ \\
\hline 2 & $3.39(2 \mathrm{H}, \mathrm{m})$ & 48.7 & $3.40(2 \mathrm{H}, \mathrm{m})$ & 48.7 \\
\hline 3 & $1.25(2 \mathrm{H}, \mathrm{m})$ & 27.1 & $1.26(2 \mathrm{H}, \mathrm{m})$ & 27.2 \\
\hline 4 & $1.57(2 \mathrm{H}, \mathrm{m})$ & 25.4 & $1.57(2 \mathrm{H}, \mathrm{m})$ & 25.3 \\
\hline 5 & $1.54(2 \mathrm{H}, \mathrm{m})$ & 26.3 & $1.54(2 \mathrm{H}, \mathrm{m})$ & 26.4 \\
\hline 6 & $3.58(2 \mathrm{H}, \mathrm{m})$ & 43.3 & $3.59(2 \mathrm{H}, \mathrm{m})$ & 43.3 \\
\hline $1^{\prime}$ & & 131.2 & & 131.9 \\
\hline $2^{\prime}$ & 7.31 (br d, 8.7) & 130.9 & $7.05(\mathrm{~d}, 1.8)$ & 113.5 \\
\hline $3^{\prime}$ & 7.07 (br d, 8.7) & 117.7 & & 150.8 \\
\hline $4^{\prime}$ & & 159.2 & & 148.2 \\
\hline $5^{\prime}$ & 7.07 (br d, 8.7) & 117.7 & $7.11(\mathrm{~d}, 8.4)$ & 117.6 \\
\hline $6^{\prime}$ & 7.31 (br d, 8.7) & 130.9 & $6.92(\mathrm{dd}, 8.4,1.8)$ & 122.9 \\
\hline $7^{\prime}$ & $6.64(\mathrm{~d}, 12.6)$ & 134.0 & $6.64(\mathrm{~d}, 12.6)$ & 134.1 \\
\hline $8^{\prime}$ & $5.97(\mathrm{~d}, 12.6)$ & 122.6 & $6.00(\mathrm{~d}, 12.6)$ & 122.9 \\
\hline $9^{\prime}$ & & 169.8 & & 169.8 \\
\hline $1^{\prime \prime}$ & $4.96(\mathrm{~d}, 7.8)$ & 101.7 & $4.96(\mathrm{~d}, 7.7)$ & 102.1 \\
\hline $2^{\prime \prime}$ & $3.51(\mathrm{dd}, 9.1,7.8)$ & 74.6 & $3.56(\mathrm{~m})$ & 74.6 \\
\hline $3^{\prime \prime}$ & $3.62(\mathrm{dd}, 9.1,8.9)$ & 76.3 & $3.62(\mathrm{dd}, 9.1,8.9)$ & 76.2 \\
\hline $4^{\prime \prime}$ & $3.66(\mathrm{~m})$ & 80.1 & $3.68(\mathrm{dd}, 9.7,8.9)$ & 80.1 \\
\hline $5^{\prime \prime}$ & $3.59(\mathrm{~m})$ & 76.7 & $3.55(\mathrm{~m})$ & 76.7 \\
\hline $6^{\prime \prime}$ & $3.89(2 \mathrm{H}, \mathrm{m})$ & 61.6 & $3.87(2 \mathrm{H}, \mathrm{m})$ & 61.6 \\
\hline $1^{\prime \prime \prime}$ & $4.43(\mathrm{~d}, 7.9 \mathrm{~Hz})$ & 104.6 & $4.44(\mathrm{~d}, 7.9)$ & 104.6 \\
\hline $2^{\prime \prime \prime}$ & $3.23(\mathrm{dd}, 9.2,7.9)$ & 74.9 & $3.23(\mathrm{dd}, 9.1,7.9)$ & 74.9 \\
\hline $3^{\prime \prime \prime}$ & $3.36(\mathrm{~m})$ & 77.9 & $3.37(\mathrm{dd}, 9.1,8.9)$ & 77.9 \\
\hline $4^{\prime \prime \prime}$ & $3.32(\mathrm{~m})$ & 71.4 & $3.32(\mathrm{~m})$ & 71.4 \\
\hline $5^{\prime \prime \prime}$ & $3.35(\mathrm{~m})$ & 78.2 & $3.34(\mathrm{~m})$ & 78.2 \\
\hline $6^{\prime \prime \prime}$ & $\begin{array}{l}3.88(\mathrm{dd}, 12.0,2.1) \\
3.66(\mathrm{~m})\end{array}$ & 62.5 & $\begin{array}{l}3.88(\mathrm{~m}) \\
3.66(\mathrm{~m})\end{array}$ & 62.4 \\
\hline 3'-OMe & & & $3.82(3 \mathrm{H}, \mathrm{s})$ & 56.7 \\
\hline
\end{tabular}

(E)- $N$-(Tetrahydro-2H-pyran-2-yl)cinnamamide (9) was first reported as a natural product. It has also been synthesized [21]. The NMR data for compound 9 are presented in this paper. The other known compounds, which are piperine (10) [22], methyl piperate (11) [23], piperanine (12) [24], pipernonaline (13) [25], piperchabamide B (14) [9], piperolein-B (15) [22], 3-phenyl-1-(piperidin-1-yl)propan-1-one (16) [17] (E)-3phenyl-1-(piperidin-1-yl)prop-2-en-1-one (17) [17], transfagaramide (18) [26], pipercide (19) [27], guineensine (20) [27], dihydropiperlonguminine (21) [25], 5,6-dihydro$1 H$-pyridin-2-one (22) [28], 3-chloro-4-hydroxy-2piperidone (23) [29], octahydro-4-hydroxy-3 $\alpha$-methyl-7methylene- $\alpha$-(1-methylethyl)- $1 H$-indene-1-methanol (24) [30], alismoxide (25) [31] (4S,4aS, 6S, 8aS)-octahydro-4hydroxy-4,8a-dimethyl-6-(1-methylethenyl)naphthalen1(2H)-one (26) [16], ent-4(15)-eudesmene-1 $\beta, 6 \alpha$-diol (27) [32], methylsalicylate-2- $O$ - $\beta$-D-glucopyranoside
Table $4{ }^{1} \mathrm{H}(800 \mathrm{MHz})$ and ${ }^{13} \mathrm{C}$ NMR $(201 \mathrm{MHz})$ data of 7 and 8 in methanol- $d_{4}$

\begin{tabular}{|c|c|c|c|c|}
\hline \multirow[t]{2}{*}{ No. } & \multicolumn{2}{|l|}{7} & \multicolumn{2}{|l|}{8} \\
\hline & $\delta_{\mathrm{H}}$ & $\delta_{\mathrm{C}}$ & $\delta_{\mathrm{H}}$ & $\delta_{\mathrm{C}}$ \\
\hline 1 & & 138.2 & & 138.2 \\
\hline 2,6 & $7.42(2 \mathrm{H}, \mathrm{br} d, 7.5)$ & 127.6 & $7.40(2 \mathrm{H}$, br d, 7.5) & 127.5 \\
\hline 3,5 & $7.30(2 \mathrm{H}$, br t, 7.5$)$ & 129.6 & $7.29(2 \mathrm{H}$, br t, 7.5$)$ & 129.6 \\
\hline 4 & $7.21(\mathrm{br} \mathrm{t}, 7.5)$ & 128.7 & $7.22($ br t, 7.5$)$ & 128.7 \\
\hline 7 & $6.69(\mathrm{br} \mathrm{d}, 16.0)$ & 133.6 & $6.68(\mathrm{br} \mathrm{d}, 16.0)$ & 133.8 \\
\hline 8 & $6.37(\mathrm{dt}, 16.0,5.9)$ & 126.7 & $6.36(\mathrm{dt}, 16.0,6.0)$ & 126.7 \\
\hline 9 & $\begin{array}{l}4.54(\mathrm{ddd}, 12.8,5.9,1.6) \\
4.35(\mathrm{ddd}, 12.8,5.9,1.6)\end{array}$ & 70.9 & $\begin{array}{l}4.51(\mathrm{ddd}, 12.5, \\
6.0,1.5) \\
4.32(\mathrm{ddd}, 12.5, \\
6.0,1.5)\end{array}$ & 70.8 \\
\hline $1^{\prime}$ & $4.51(\mathrm{~d}, 7.8)$ & 102.1 & $4.40(\mathrm{~d}, 7.9)$ & 103.1 \\
\hline $2^{\prime}$ & $3.47(\mathrm{dd}, 8.9,7.8)$ & 83.5 & $3.30(\mathrm{~m})$ & 74.7 \\
\hline $3^{\prime}$ & $3.57(\mathrm{dd}, 9.2,8.9)$ & 78.1 & $3.52(\mathrm{~m})$ & 76.7 \\
\hline $4^{\prime}$ & $3.30(\mathrm{~m})$ & 71.4 & $3.53(\mathrm{~m})$ & 82.3 \\
\hline $5^{\prime}$ & $3.27(\mathrm{~m})$ & 77.8 & $3.42(\mathrm{~m})$ & 76.2 \\
\hline $\begin{array}{l}6^{\prime} \mathrm{a} \\
6^{\prime} \mathrm{b}\end{array}$ & $\begin{array}{l}3.86(\mathrm{~m}) \\
3.66(\mathrm{~m})\end{array}$ & 62.7 & $\begin{array}{l}3.91(\mathrm{dd}, 12.1,2.6) \\
3.83(\mathrm{dd}, 12.1,4.6)\end{array}$ & 62.1 \\
\hline $1^{\prime \prime}$ & $4.66(\mathrm{~d}, 7.9)$ & 105.1 & $4.38(\mathrm{~d}, 7.9)$ & 104.9 \\
\hline $2^{\prime \prime}$ & $3.31(\mathrm{~m})$ & 75.7 & $3.22(\mathrm{~m})$ & 75.1 \\
\hline $3^{\prime \prime}$ & $3.53(\mathrm{dd}, 9.1,9.0)$ & 76.2 & $3.27(\mathrm{~m})$ & 77.8 \\
\hline $4^{\prime \prime}$ & $3.59(\mathrm{dd}, 9.4,9.1)$ & 80.5 & $3.28(\mathrm{~m})$ & 71.9 \\
\hline $5^{\prime \prime}$ & $3.41(\mathrm{~m})$ & 76.8 & $3.56(\mathrm{~m})$ & 76.6 \\
\hline $6^{\prime \prime}$ & $3.85(2 \mathrm{H}, \mathrm{m})$ & 61.8 & $\begin{array}{l}4.25(\mathrm{dd}, 10.7,2.2) \\
3.65(\mathrm{~m})\end{array}$ & 70.1 \\
\hline $1^{\prime \prime \prime}$ & $4.39(\mathrm{~d}, 7.9)$ & 104.6 & $4.31(\mathrm{~d}, 7.7)$ & 104.4 \\
\hline $2^{\prime \prime \prime}$ & $3.20(\mathrm{dd}, 9.2,7.9)$ & 74.9 & $3.22(\mathrm{~m})$ & 74.9 \\
\hline $3^{\prime \prime \prime}$ & $3.34(\mathrm{~m})$ & 77.9 & $3.37(\mathrm{~m})$ & 77.7 \\
\hline $4^{\prime \prime \prime}$ & $3.30(\mathrm{~m})$ & 71.4 & $3.28(\mathrm{~m})$ & 71.5 \\
\hline $5^{\prime \prime \prime}$ & $3.34(\mathrm{~m})$ & 78.0 & $3.35(\mathrm{~m})$ & 77.9 \\
\hline $6^{\prime \prime \prime}$ & $\begin{array}{l}3.86(\mathrm{~m}) \\
3.66(\mathrm{~m})\end{array}$ & 62.4 & $\begin{array}{l}3.86(\mathrm{dd}, 12.1,1.8) \\
3.66(\mathrm{~m})\end{array}$ & 62.7 \\
\hline
\end{tabular}

(28) [33], rozin (29) [19], piperchabaoside A (30) [20] $(6 S, 9 R)$-roseoside (31) [34], and 2'-O-methyluridine (32) [35], were identified by comparing their spectroscopic data with those in the literature.

\subsection{In Vitro Platelet Aggregation Assay}

All the isolates (1-32) were evaluated for inhibitory activity against mouse platelet aggregation induced by the peptide H-Ala-Tyr-Pro-Gly-Lys-Phe-- $\mathrm{NH}_{2}$ (AYPGKF-NH ${ }_{2}$ ). As shown in Table 5, (E)- $N$-cinnamoyl-2-methoxypiperidine (1), (E)- $N$-(tetrahydro-2 $H$-pyran-2-yl)cinnamamide (9), 3-phenyl-1-(piperidin-1-yl)propan-1-one (16), and 2 '-O-methyluridine (32) showed weak inhibitory effects at a concentration of $100 \mu \mathrm{M}$, with inhibitory rates of $21.4 \%$ (75 $\mu \mathrm{M}$ AYPGKF- $\left.\mathrm{NH}_{2}\right), 35.5 \%$ (75 $\mu \mathrm{M}$ AYPGKF-NH ${ }_{2}$ ), 
Table 5 Inhibitory effects of compounds from Piper retrofractum on mouse platelet aggregation induced by AYPGKF-NH $\mathrm{N}_{2}$

\begin{tabular}{lll}
\hline Compound & Concentration $(\mu \mathrm{M})$ & Inhibition $(\%)$ \\
\hline$(E)$ - $N$-Cinnamoyl-2-methoxypiperidine (1) & 100 & $21.4^{\mathrm{b}}$ \\
$(E)$ - $N$-(Tetrahydro-2H-pyran-2-yl)cinnamamide $(\mathbf{9})$ & 150 & $52.0^{\mathrm{b}}$ \\
& 130 & $42.5^{\mathrm{b}}$ \\
& 100 & $35.5^{\mathrm{b}}$ \\
3-Phenyl-1-(piperidin-1-yl)propan-1-one (16) & 80 & $7.6^{\mathrm{b}}$ \\
2'-O-Methyluridine (32) & 100 & $26.2^{\mathrm{b}}$ \\
\hline
\end{tabular}

${ }^{a}$ Inhibition of compounds 2-8, 10-15, and 17-31 was less than $20 \%$

b Induced by $75 \mu \mathrm{M}$ AYP- $\mathrm{NH}_{2}$

${ }^{\mathrm{c}}$ Induced by $100 \mu \mathrm{M}$ AYP-NH
26.2\% (75 $\mu \mathrm{M}$ AYPGKF- $\left.\mathrm{NH}_{2}\right)$, and $36.1 \%(100 \mu \mathrm{M}$ AYPGKF- $\mathrm{NH}_{2}$ ). The strongest inhibitory activity was exhibited by $150 \mu \mathrm{M}$ of compound $\mathbf{9}$, with an inhibition of $52.0 \%$. The other tested compounds were found to be inactive.

AYPGKF-NH $\mathrm{N}_{2}$ is the gold agonist of protease-activated receptor 4 (PAR4) [36, 37], and PAR4 is believed to be a novel anti-platelet target with low bleeding liability [38, 39]. Therefore, if compound 9 were able to inhibit the aggregation of platelets induced by AYPGKF-NH ${ }_{2}$, then it would be a novel anti-platelet agent.

\section{Experimental Section}

\subsection{General Experimental Procedures}

Optical rotations were recorded using a JASCO P-1020 Polarimeter (Jasco Corp., Tokyo, Japan). Ultraviolet (UV) spectra were obtained using a Shimadzu UV-2401 PC spectrophotometer (Shimadzu, Kyoto, Japan). ${ }^{1} \mathrm{H}$ and ${ }^{13} \mathrm{C}$ Nuclear magnetic resonance (NMR) spectra were collected on a Bruker AM-400, DRX-500, Avance III600 , and Ascend ${ }^{\mathrm{TM}} 800 \mathrm{MHz}$ spectrometers (Bruker Corp., Karlsruhe, Germany) with tetramethylsilane (TMS) as an internal standard. Electrospray ionization mass spectrometry (ESIMS) and high-resolution electrospray ionization mass spectrometry (HRESIMS) analyses were performed on an API QSTAR Pulsar 1 spectrometer (Applied Biosystems/MDS Sciex, Foster City, CA, USA). HREIMS was performed on a Waters AutoSpec Premier p776 spectrometer (Waters, Milford, MA, USA). Silica gel G (80-100 and 300-400 mesh, Qingdao Meigao Chemical Co., Ltd., Qingdao, China), $\mathrm{C}_{18}$ silica gel (40-75 $\mu \mathrm{m}$, Fuji Silysia Chemical Ltd., Aichi, Japan), and Sephadex LH-20 (GE Healthcare Bio-Sciences AB, Uppsala, Sweden) were used for column chromatography, and silica gel $\mathrm{GF}_{254}$ (Qingdao Meigao Chemical Co., Ltd.) on precoated plates was used for preparative thin layer chromatography (TLC).
TLC spots were visualized under UV light at $254 \mathrm{~nm}$ and by dipping into $5 \% \mathrm{H}_{2} \mathrm{SO}_{4}$ in alcohol followed by heating. Semipreparative high-performance liquid chromatography (HPLC) was performed on an Agilent 1200 series pump (Agilent Technologies, Santa Clara, USA) equipped with a diode array detector and a Waters $\mathrm{XBridge} \mathrm{C}_{18}$ column $(5.0 \mu \mathrm{m}, \phi 10 \times 250 \mathrm{~mm})$, an Agilent Zorbax SB- $_{18}$ column $(5.0 \mu \mathrm{m}, \phi 9.4 \times 250 \mathrm{~mm})$, a Welch Ultimate AQ-C 18 column $(5.0 \mu \mathrm{m}, \phi 4.6 \times 300 \mathrm{~mm})$, a Welch Ultimate AQ- $\mathrm{C}_{18}$ column $(5.0 \mu \mathrm{m}, \phi 7.8 \times 250 \mathrm{~mm})$, and a chiral CD-Ph column (Shiseido, Japan, $5.0 \mu \mathrm{m}, \phi 4.6 \times 250 \mathrm{~mm}$ ).

\subsection{Plant Material}

Fruits of $P$. retrofractum were bought from Zay cho Market of Mandalay, Myanmar in December 2015. The plant was identified by the author Jun Yang. A voucher specimen (No. my-80) was deposited at the Key Laboratory of Economic Plants and Biotechnology, Kunming Institute of Botany, Chinese Academy of Sciences.

\subsection{Extraction and Isolation}

The air-dried fruits of $P$. retrofractum $(2.4 \mathrm{~kg})$ were extracted with $90 \% \mathrm{EtOH}(10 \mathrm{~L})$ three times under ambient temperature. The crude extract ( $260.9 \mathrm{~g}$ ) was then suspended in $\mathrm{H}_{2} \mathrm{O}$ $(1 \mathrm{~L})$ and successively partitioned with petroleum ether (PE, $3 \times 1 \mathrm{~L}$ ), ethyl acetate (EtOAc, $3 \times 1 \mathrm{~L}$ ), and $n$-butanol $(n-\mathrm{BuOH}, 3 \times 1 \mathrm{~L})$. After evaporation of the solvent in vacuum, the PE fraction $(113.1 \mathrm{~g})$, EtOAc fraction $(83.9 \mathrm{~g})$, and $n$-BuOH fraction $(43.4 \mathrm{~g})$ were obtained.

The PE fraction (A) was separated by a silica gel column via elution by PE/EtOAc $(100: 0 \rightarrow 1: 1, \mathrm{v} / \mathrm{v})$ to yield compounds $\mathbf{1 0}(5.0 \mathrm{~g})$ and $\mathbf{1 1}(3.5 \mathrm{~g})$, along with nine fractions (Fr. A-1 to Fr. A-9). Fr. A-9 was purified by a $\mathrm{C}_{18}$ silica gel column and eluted with $\mathrm{MeOH} / \mathrm{H}_{2} \mathrm{O}(10 \% \rightarrow$ $100 \%$ ), to yield seven fractions (Fr. A-9-1 to Fr. A-9-7). Fr. A-9-3 was applied to a silica gel column and eluted with PE/Acetone (20:1 $\rightarrow 1: 1)$ to afford four parts (Fr. A-9-3-1 
to Fr. A-9-3-4). Fr. A-9-3-4 was further purified by HPLC (Agilent Zorbax SB-C 18 column, $5.0 \mu \mathrm{m}, \phi 9.4 \times 250 \mathrm{~mm}$, $\mathrm{MeOH}-\mathrm{H}_{2} \mathrm{O}, 10: 90, \mathrm{v} / \mathrm{v}, 2 \mathrm{~mL} / \mathrm{min}$ ) to give compounds 9 $\left(17.5 \mathrm{mg}, t_{\mathrm{R}}=13.225 \mathrm{~min}\right)$ and $25\left(3.2 \mathrm{mg}, t_{\mathrm{R}}=6.482 \mathrm{~min}\right)$. Fr. A-9-4 was separated on a silica gel column, with elution by PE/Acetone (15:1), to provide Fr. A-9-4-1 to Fr. A-94-3. Fr. A-9-4-1 was further purified by HPLC (Agilent Zorbax SB-C ${ }_{18}$ column, $5.0 \mu \mathrm{m}, \phi 9.4 \times 250 \mathrm{~mm}, \mathrm{MeOH}-$ $\left.\mathrm{H}_{2} \mathrm{O}, 60: 40,2 \mathrm{~mL} / \mathrm{min}\right)$ to afford compounds $1(1.5 \mathrm{mg}$, $t_{\mathrm{R}}=52.230 \mathrm{~min}$ ) and $16\left(4.0 \mathrm{mg}, t_{\mathrm{R}}=48.003 \mathrm{~min}\right)$. Fr. A-9-4-2 was separated into two parts by a Sephadex LH-20 column, eluted with $\mathrm{MeOH}$. Fr. A-9-4-2-1 was then purified by HPLC (Welch Ultimate AQ-C ${ }_{18}$ column, $5.0 \mu \mathrm{m}, \phi$ $7.8 \times 250 \mathrm{~mm}, \mathrm{CH}_{3} \mathrm{CN}-\mathrm{H}_{2} \mathrm{O}, 30: 70,2 \mathrm{~mL} / \mathrm{min}$ ) to afford compounds $24\left(1.7 \mathrm{mg}, t_{\mathrm{R}}=56.221 \mathrm{~min}\right), \mathbf{2 6}\left(0.7 \mathrm{mg}, t_{\mathrm{R}}=\right.$ $63.039 \mathrm{~min})$, and $27\left(21.3 \mathrm{mg}, t_{\mathrm{R}}=36.159 \mathrm{~min}\right)$.

Compound 17 ( $40.0 \mathrm{mg}, t_{\mathrm{R}}=30.258 \mathrm{~min}$ ) was obtained from Fr. A-9-4-2-2 by HPLC (Agilent Zorbax SB-C ${ }_{18}$ column, $5.0 \mu \mathrm{m}, \phi 9.4 \times 250 \mathrm{~mm}, \mathrm{CH}_{3} \mathrm{CN}-\mathrm{H}_{2} \mathrm{O}, 40: 60,2 \mathrm{~mL} /$ min). Fr. A-9-4-3 was applied to a Sephadex LH-20 column and eluted with $\mathrm{MeOH}$ to afford compound 18 (17.5 mg). The remaining part was then further purified by HPLC (Agilent Zorbax SB-C ${ }_{18}$ column, $5.0 \mu \mathrm{m}, \phi 9.4 \times 250 \mathrm{~mm}$, $\mathrm{MeOH}-\mathrm{H}_{2} \mathrm{O}, 60: 40,2 \mathrm{~mL} / \mathrm{min}$ ) to provide compound $21\left(9.4 \mathrm{mg}, t_{\mathrm{R}}=36.088 \mathrm{~min}\right)$. Fr. A-9-5 was applied to a silica gel column, with elution by PE/EtOAc (20:1), and a Sephadex LH-20 column, with elution by $\mathrm{MeOH}$, yielding compound 12 (7.4 mg). Fr. A-9-7 was separated by a silica gel column via elution by PE/Acetone (10:1) to afford compounds 13 (5.7 g), 19 (7.2 g), and 20 (1.2 g). Finally, the remaining part of Fr. A-9-7 was applied to a Sephadex LH-20 column, eluted with $\mathrm{MeOH}$ and then further purified by HPLC (Agilent Zorbax SB-C ${ }_{18}$ column, $5.0 \mu \mathrm{m}, \phi$ $\left.9.4 \times 250 \mathrm{~mm}, \mathrm{MeOH}-\mathrm{H}_{2} \mathrm{O}, 85: 15,2 \mathrm{~mL} / \mathrm{min}\right)$, yielding compounds $14\left(4.5 \mathrm{mg}, t_{\mathrm{R}}=25.337 \mathrm{~min}\right)$ and $15(4.5 \mathrm{mg}$, $\left.t_{\mathrm{R}}=17.900 \mathrm{~min}\right)$.

The $n-\mathrm{BuOH}$ fraction (C) was separated by a silica gel column via elution by $\mathrm{CH}_{2} \mathrm{Cl}_{2} / \mathrm{MeOH}(20: 1 \rightarrow 1: 1, \mathrm{v} / \mathrm{v})$, to yield five fractions (Fr. C-1 to Fr. C-5).

Fr. C-1 was applied to a $\mathrm{C}_{18}$ silica gel column and eluted with $\mathrm{MeOH} / \mathrm{H}_{2} \mathrm{O}(5 \% \rightarrow 100 \%)$ to yield fractions Fr. C-1-1 and Fr. C-1-2. Fr.C-1-1 was further purified using HPLC (Welch Ultimate AQ- ${ }_{18}$ column, $5.0 \mu \mathrm{m}, \phi 7.8 \times 250 \mathrm{~mm}$, $\mathrm{MeOH}-\mathrm{H}_{2} \mathrm{O}, 7: 93,2 \mathrm{~mL} / \mathrm{min}$ ) to afford compound $\mathbf{2 3}$ $\left(2.3 \mathrm{mg}, t_{\mathrm{R}}=10.681 \mathrm{~min}\right)$. Fr. C-1-2 was applied to a Sephadex LH-20 column, eluted with $\mathrm{MeOH}$, and then purified by HPLC (Welch Ultimate AQ- ${ }_{18}$ column, $5.0 \mu \mathrm{m}, \phi 7.8 \times$ $\left.250 \mathrm{~mm}, \mathrm{MeOH}-\mathrm{H}_{2} \mathrm{O}, 7: 93,2 \mathrm{~mL} / \mathrm{min}\right)$, and compounds 2 $\left(4.0 \mathrm{mg}, t_{\mathrm{R}}=36.216 \mathrm{~min}\right)$ and $22\left(7.4 \mathrm{mg}, t_{\mathrm{R}}=15.353 \mathrm{~min}\right)$ were obtained.

Fr. C-2 was separated by a $\mathrm{C}_{18}$ silica gel column via elution by $\mathrm{MeOH} / \mathrm{H}_{2} \mathrm{O}(5 \% \rightarrow 100 \%)$, to yield four fractions (Fr. C-2-1 to Fr. C-2-4). Fr. C-2-2 was applied to a Sephadex LH-20 column, eluted with $\mathrm{MeOH}$, and then purified by HPLC (Welch Ultimate AQ- $\mathrm{C}_{18}$ column, $\left.5.0 \mu \mathrm{m}, \phi 7.8 \times 250 \mathrm{~mm}, \mathrm{MeOH}-\mathrm{H}_{2} \mathrm{O}, 7: 93,2 \mathrm{~mL} / \mathrm{min}\right)$ to provide compound $32\left(1.8 \mathrm{mg}, t_{\mathrm{R}}=24.453 \mathrm{~min}\right)$. Fr. C-2-3 was applied to a Sephadex LH-20 column and eluted with $\mathrm{MeOH}$ to afford two fractions. Fr. C-2-3-1 was purified by HPLC (Welch Ultimate AQ- ${ }_{18}$ column, $5.0 \mu \mathrm{m}, \phi 7.8 \times$ $250 \mathrm{~mm}, \mathrm{MeOH}-\mathrm{H}_{2} \mathrm{O}, 40: 60,2 \mathrm{~mL} / \mathrm{min}$ ) to give compound $31\left(10.7 \mathrm{mg}, t_{\mathrm{R}}=8.977 \mathrm{~min}\right)$, and compound $28(1.2 \mathrm{mg}$, $t_{\mathrm{R}}=9.417 \mathrm{~min}$ ) was obtained from Fr. C-2-3-2, purified by HPLC (Welch Ultimate AQ- $\mathrm{C}_{18}$ column, $5.0 \mu \mathrm{m}, \phi 7.8$ $\left.\times 250 \mathrm{~mm}, \mathrm{MeOH}-\mathrm{H}_{2} \mathrm{O}, 38: 52,2 \mathrm{~mL} / \mathrm{min}\right)$. Fr. C-2-4 was separated by a silica gel column, with elution by $\mathrm{CH}_{2} \mathrm{Cl}_{2} /$ $\mathrm{MeOH}(50: 1 \rightarrow 1: 1, \mathrm{v} / \mathrm{v})$, and then purified by HPLC (Welch Ultimate AQ- $\mathrm{C}_{18}$ column, $5.0 \mu \mathrm{m}, \phi 7.8 \times 250 \mathrm{~mm}, \mathrm{MeOH}-$ $\left.\mathrm{H}_{2} \mathrm{O}, 65: 35,2 \mathrm{~mL} / \mathrm{min}\right)$, and compound 29 (3.6 mg, $t_{\mathrm{R}}=$ $6.597 \mathrm{~min}$ ) was obtained.

Fr. C-4 was applied to a $\mathrm{C}_{18}$ silica gel column and eluted with $\mathrm{MeOH} / \mathrm{H}_{2} \mathrm{O}(5 \% \rightarrow 100 \%)$ to yield fractions Fr. C-4-1 and Fr. C-4-2. Fr. C-4-1 was further purified by a silica gel column, with elution by EtOAc/MeOH (15:1), to provide compound 30 (8.6 mg). Fr. C-4-2 was applied to a Sephadex LH-20 column, eluted with $\mathrm{MeOH}$, and then purified by HPLC (Welch Ultimate AQ- $\mathrm{C}_{18}$ column, $5.0 \mu \mathrm{m}, \phi 7.8$ $\left.\times 250 \mathrm{~mm}, \mathrm{MeOH}-\mathrm{H}_{2} \mathrm{O}, 27: 73,2 \mathrm{~mL} / \mathrm{min}\right)$ to afford compounds $5\left(0.7 \mathrm{mg}, t_{\mathrm{R}}=7.802 \mathrm{~min}\right)$ and $6\left(0.8 \mathrm{mg}, t_{\mathrm{R}}=\right.$ $14.055 \mathrm{~min})$.

Fr. C-5 was separated on a $\mathrm{C}_{18}$ silica gel column via elution by $\mathrm{MeOH} / \mathrm{H}_{2} \mathrm{O}(5 \% \rightarrow 100 \%)$, to yield fraction Fr. C-5-1. Then, Fr. C-5-1 was applied to a Sephadex LH-20 column and eluted with $\mathrm{MeOH}$ to yield two fractions. Fr. C-5-1-1 was further applied to a silica gel column, eluted with EtOAc/MeOH (10:1), and then purified by HPLC (Welch Ultimate AQ- $\mathrm{C}_{18}$ column, $5.0 \mu \mathrm{m}, \phi 7.8 \times 250 \mathrm{~mm}$, $\mathrm{CH}_{3} \mathrm{CN}-\mathrm{H}_{2} \mathrm{O}, 15: 85,2 \mathrm{~mL} / \mathrm{min}$ ) to afford compounds 3 $\left(2.1 \mathrm{mg}, t_{\mathrm{R}}=14.066 \mathrm{~min}\right), 4\left(2.1 \mathrm{mg}, t_{\mathrm{R}}=11.151 \mathrm{~min}\right), 7$ $\left(0.5 \mathrm{mg}, t_{\mathrm{R}}=15.715 \mathrm{~min}\right)$, and $8\left(0.7 \mathrm{mg}, t_{\mathrm{R}}=26.034 \mathrm{~min}\right)$.

\subsection{Spectroscopic Data of Compounds}

\subsection{1 (E)-N-Cinnamoyl-2-methoxypiperidine (1)}

White amorphous powder; $[\alpha]_{\mathrm{D}}^{23}-15.3(c=0.15, \mathrm{MeOH})$; UV (MeOH) $\lambda_{\text {max }}(\log \varepsilon) 399$ (1.29), 279 (3.66), 217 (3.52), 205 (3.53) nm; ${ }^{1} \mathrm{H}$ NMR and ${ }^{13} \mathrm{C}$ NMR data see Table 1; ESIMS (positive) $m / z 268[\mathrm{M}+\mathrm{Na}]^{+}, 513[2 \mathrm{M}+\mathrm{Na}]^{+}$; HREIMS $m / z, 245.1423[\mathrm{M}]^{+}$(calcd for $\mathrm{C}_{15} \mathrm{H}_{19} \mathrm{NO}_{2}$, 245.1416). 
3.4.2 (R)-1-(2-0xopyrrolidin-3-yl)-5,6-dihydropyridin-2(1H )-one (2)

White amorphous powder; $[\alpha]_{\mathrm{D}}^{20}-15.6(c=0.23$, MeOH $)$; $\mathrm{UV}(\mathrm{MeOH}) \lambda_{\max }(\log \varepsilon) 246$ (2.32), 232 (2.27), 196 (3.05) $\mathrm{nm} ;{ }^{1} \mathrm{H}$ NMR $\left(\mathrm{CD}_{3} \mathrm{OD}, 500 \mathrm{MHz}\right) \delta_{\mathrm{H}} 6.76(\mathrm{dt}, J=9.8$, $4.2 \mathrm{~Hz}, \mathrm{H}-4), 6.23$ (m, H-3'), 5.87 (dt, $J=9.8,1.8 \mathrm{~Hz}, \mathrm{H}-3$ ), 3.38 (2H, m, $\left.\mathrm{H}_{2}-6\right), 2.51$ (m, H-5'a), 2.51 (m, H-4'a), 2.44 (2H, m, $\left.\mathrm{H}_{2}-5\right), 2.36$ (m, H-5'b), 2.01 (m, H-4'b); ${ }^{13} \mathrm{C}$ NMR $\left(\mathrm{CD}_{3} \mathrm{OD}, 126 \mathrm{MHz}\right) \delta_{\mathrm{C}} 180.7\left(\mathrm{C}-2^{\prime}\right), 166.6(\mathrm{C}-2), 143.6$ (C-4), 125.2 (C-3), 65.0 (C-3'), 39.7 (C-6), 30.5 (C-5'), 25.7 (C-4'), 25.3 (C-5); ESIMS (positive) $\mathrm{m} / 2.203[\mathrm{M}+\mathrm{Na}]^{+}$, $383[2 \mathrm{M}+\mathrm{Na}]^{+}$; HRESIMS (positive) $\mathrm{m} / z 203.0793[\mathrm{M}+$ $\mathrm{Na}]^{+}$(calcd for $\mathrm{C}_{9} \mathrm{H}_{12} \mathrm{~N}_{2} \mathrm{NaO}_{2}, 203.0797$ ).

\subsubsection{Retrofractoside A (3)}

White amorphous powder; $[\alpha]_{\mathrm{D}}^{19}-120.2(c=0.10, \mathrm{MeOH})$; $\mathrm{UV}(\mathrm{MeOH}) \lambda_{\max }(\log \varepsilon) 290$ (4.33), 248 (3.93), 213 (4.28), 207 (4.28), 196 (4.33) nm; ${ }^{1} \mathrm{H}$ NMR and ${ }^{13} \mathrm{C}$ NMR data see Table 2; ESIMS (positive) $m / z 594[\mathrm{M}+\mathrm{Na}]^{+}$; HRESIMS (positive) $\mathrm{m} / z 594.2160[\mathrm{M}+\mathrm{Na}]^{+}$(calcd for $\mathrm{C}_{26} \mathrm{H}_{37} \mathrm{NNaO}_{13}$, 594.2163).

\subsubsection{Retrofractoside B (4)}

White amorphous powder; $[\alpha]_{\mathrm{D}}^{21}-73.5(c=0.12, \mathrm{MeOH})$; $\mathrm{UV}(\mathrm{MeOH}) \lambda_{\max }(\log \varepsilon) 264$ (3.95), 242 (3.82), 197 (4.30) $\mathrm{nm} ;{ }^{1} \mathrm{H}$ NMR and ${ }^{13} \mathrm{C}$ NMR data see Table 2; ESIMS (positive) $m / z 594[\mathrm{M}+\mathrm{Na}]^{+}$; HRESIMS (positive) $\mathrm{m} / z 594.2161$ $[\mathrm{M}+\mathrm{Na}]^{+}$(calcd for $\mathrm{C}_{26} \mathrm{H}_{37} \mathrm{NNaO}_{13}, 594.2163$ ).

\subsubsection{Retrofractoside C (5)}

White amorphous powder; $[\alpha]_{\mathrm{D}}^{27}-67.5(c=0.04, \mathrm{MeOH})$; $\mathrm{UV}(\mathrm{MeOH}) \lambda_{\max }(\log \varepsilon) 265$ (3.83), $203(4.06) \mathrm{nm} ;{ }^{1} \mathrm{H}$ NMR and ${ }^{13} \mathrm{C}$ NMR data see Table 3; ESIMS (positive) $\mathrm{m} / \mathrm{z}$ $578[\mathrm{M}+\mathrm{Na}]^{+}$; HRESIMS (positive) $\mathrm{m} / z$ 578.2206 $[\mathrm{M}+$ $\mathrm{Na}]^{+}$(calcd for $\mathrm{C}_{26} \mathrm{H}_{37} \mathrm{NNaO}_{12}, 578.2214$ ).

\subsubsection{Retrofractoside D (6)}

White amorphous powder; $[\alpha]_{\mathrm{D}}^{22}-52.6(c=0.10, \mathrm{MeOH})$; $\mathrm{UV}(\mathrm{MeOH}) \lambda_{\max }(\log \varepsilon) 293$ (3.96), 266 (4.16), 205 (4.46) $\mathrm{nm} ;{ }^{1} \mathrm{H}$ NMR and ${ }^{13} \mathrm{C}$ NMR data see Table 3; ESIMS (positive) $\mathrm{m} / z 608[\mathrm{M}+\mathrm{Na}]^{+}$; HRESIMS (positive) $\mathrm{m} / z 608.2317$ $[\mathrm{M}+\mathrm{Na}]^{+}$(calcd for $\mathrm{C}_{27} \mathrm{H}_{39} \mathrm{NNaO}_{13}, 608.2319$ ).

\subsubsection{Retrofractoside E (7)}

Brown syrup; $[\alpha]_{\mathrm{D}}^{19}-51.1(c=0.10, \mathrm{MeOH}) ; \mathrm{UV}(\mathrm{MeOH})$ $\lambda_{\max }(\log \varepsilon) 250$ (3.51), 231 (3.42), $197(4.03) \mathrm{nm} ;{ }^{1} \mathrm{H}$ NMR and ${ }^{13} \mathrm{C}$ NMR data see Table 4; ESIMS (positive) $\mathrm{m} / \mathrm{z} 643$
$[\mathrm{M}+\mathrm{Na}]^{+}$; HRESIMS (positive) $\mathrm{m} / z$ $643.2218[\mathrm{M}+\mathrm{Na}]^{+}$ (calcd for $\mathrm{C}_{27} \mathrm{H}_{40} \mathrm{NaO}_{16}, 643.2214$ ).

\subsubsection{Retrofractoside F (8)}

Brown syrup; $[\alpha]_{\mathrm{D}}^{19}-67.5(c=0.08, \mathrm{MeOH}) ; \mathrm{UV}(\mathrm{MeOH})$ $\lambda_{\max }(\log \varepsilon) 249$ (4.29), 224 (3.90), 200 (4.51) nm; ${ }^{1} \mathrm{H}$ NMR and ${ }^{13} \mathrm{C}$ NMR data see Table 4; ESIMS (positive) $\mathrm{m} / \mathrm{z} 643$ [M $+\mathrm{Na}^{+}$; HRESIMS (positive) $\mathrm{m} / z 643.2217[\mathrm{M}+\mathrm{Na}]^{+}($calcd for $\left.\mathrm{C}_{27} \mathrm{H}_{40} \mathrm{NaO}_{16}, 643.2214\right)$.

\subsection{9 (E)-N-(Tetrahydro-2H-pyran-2-yl)cinnamamide (9)}

White amorphous powder; $[\alpha]_{\mathrm{D}}^{22}-7.8(c=0.07, \mathrm{MeOH}) ; \mathrm{UV}$ (MeOH) $\lambda_{\max }(\log \varepsilon) 322(1.71), 276(2.36), 207(2.76) \mathrm{nm} ;{ }^{1} \mathrm{H}$ $\mathrm{NMR}\left(\mathrm{CDCl}_{3}, 600 \mathrm{MHz}\right) \delta_{\mathrm{H}} 7.66(\mathrm{~d}, J=15.6 \mathrm{~Hz}, \mathrm{H}-7), 7.50$ (2H, m, H-2,6), 7.37 (2H, m, H-3,5), 7.36 (m, H-4), 6.36 (d, $J$ $=15.6 \mathrm{~Hz}, \mathrm{H}-8), 5.98(\mathrm{br} \mathrm{d}, J=8.3 \mathrm{~Hz}, \mathrm{NH}), 5.26\left(\mathrm{~m}, \mathrm{H}-2^{\prime}\right)$, 4.01 (m, H-6'a), 3.66 (td, $\left.J=11.2,3.5 \mathrm{~Hz}, \mathrm{H}-6^{\prime} \mathrm{b}\right), 1.91$ (m, H-4'a), 1.88 (m, H-3'a), 1.65 (m, H-4'b), 1.55 (2H, m, H-5'), $1.45(\mathrm{~m}, \mathrm{H}-3 \mathrm{\prime} \mathrm{b}) ;{ }^{13} \mathrm{C} \mathrm{NMR}\left(\mathrm{CDCl}_{3}, 151 \mathrm{MHz}\right) \delta_{\mathrm{C}} 165.2(\mathrm{C}-9)$, 142.4 (C-7), 134.8 (C-1), 130.0 (C-4), 129.0 (C-3,5), 128.0 (C-2,6), 120.4 (C-8), 78.1 (C-2'), 67.6 (C-6'), 31.9 (C-3'), 25.2 (C-5'), $23.0\left(\mathrm{C}-4^{\prime}\right.$ ); ESIMS (positive) $\mathrm{m} / z 254[\mathrm{M}+\mathrm{Na}]^{+}, 485$ $[2 \mathrm{M}+\mathrm{Na}]^{+}$; HRESIMS (positive) $\mathrm{m} / 2$ 254.1152 $[\mathrm{M}+\mathrm{Na}]^{+}$ (calcd for $\mathrm{C}_{14} \mathrm{H}_{17} \mathrm{NNaO}_{2}, 254.1157$ ).

\subsection{Acidic Hydrolysis of Piperchabaoside A (30)}

Piperchabaoside A $(4.6 \mathrm{mg})$ was dissolved in $2 \mathrm{M} \mathrm{HCl}$ $(1 \mathrm{~mL})$ and stirred at $90{ }^{\circ} \mathrm{C}$ for $3 \mathrm{~h}$. After cooling, the solution was evaporated until dry under reduced pressure. The reaction mixture was purified by silica gel column chromatography $\left(\mathrm{CH}_{2} \mathrm{Cl}_{2}-\mathrm{MeOH}-\mathrm{H}_{2} \mathrm{O}, 500: 10: 0,300: 10: 0\right.$, 200:10:1, 100:10:1) to afford D-glucopyranose (1.2 mg), which was identified based on its ${ }^{1} \mathrm{H}$ NMR spectrum and optical rotation value: $[\alpha]_{\mathrm{D}}^{21}+23.9\left(c 0.12, \mathrm{H}_{2} \mathrm{O}\right)[40]$.

\subsection{In Vitro Platelet Aggregation Assay}

The inhibitory effects of compounds against ICR mice platelet aggregation induced by AYPGKF- $\mathrm{NH}_{2}$ were evaluated according to previously published methods [41-44].

\subsubsection{Animals}

Adult Institute of Cancer Research (ICR) mice (30-40 g) were obtained from Nanjing Qinglongshan Animal Centre (Nanjing, Jiangsu province, China). All animals were housed under controlled temperature $\left(21-25{ }^{\circ} \mathrm{C}\right)$ and light $(12 \mathrm{~h}$ light, $12 \mathrm{~h}$ dark) with ad libitum access to food and water for one week before the experiments. All the experiments were performed according to the guidelines and the regulations of 
the Ethical Committee of China Pharmaceutical University (CPU2016-S07, 5 March 2016).

\subsubsection{Materials and Reagents}

AYPGKF-NH ${ }_{2}$ was purchased from Ningbo Kangbei biochemical Co. Ltd. (Ningbo, Zhejiang province, China). All other chemicals used in this study were of analytical grade.

\subsubsection{Platelet Preparation}

Blood was withdrawn from ICR mice through the abdominal aorta and then anticoagulated with $3.2 \%$ sodium citrate (1:9 citrate/blood, v/v). Platelet-rich plasma (PRP) was obtained by centrifugation at $1080 \mathrm{rpm}$ for $10 \mathrm{~min}$. To prepare the gel-filtered platelets, PRP was applied to a column packed with Sepharose 2B beads and eluted with Tyrode's buffer into a series of $15 \mathrm{~mL}$ tubes [41,43]. The collected platelets in each tube were counted, combined, and adjusted to $2.5 \times$ $10^{8} / \mathrm{mL}$ using Tyrode's buffer.

\subsubsection{Platelet Aggregation Assay}

In vitro platelet aggregation was measured according to the turbidimetric method, using a four-channel aggregometer (LBY-NJ4, Pulisheng Instrument Co. Ltd., Beijing, China) $[42,44]$. Gel-filtered ICR mice platelets were preincubated with samples or vehicles for $5 \mathrm{~min}$ at $37^{\circ} \mathrm{C}$. Then, platelet aggregation was induced by AYPGKF- $\mathrm{NH}_{2}$. The maximum aggregation rate was measured within 5 min with continuous stirring. The light transmittance was calibrated with Tyrode's buffer. The percentage (\%) of inhibition of platelet aggregation was calculated by the following formula: $[(\mathrm{X}-\mathrm{Y}) / \mathrm{X}] \times 100 \%$, where $\mathrm{X}$ is the maximum aggregation rate of vehicle-treated gel-filtered platelets and $\mathrm{Y}$ is the maximum aggregation rate of sample-treated gel-filtered platelets.

\section{Conclusion}

The phytochemical investigation of the fruits of Piper retrofractum in this study led to the identification of 32 compounds, including two new amides, four new amide glucosides, and two new phenylpropanoid glucosides. In vitro platelet aggregation assays of all the isolates were conducted, and the results showed that $(E)-N$-(tetrahydro$2 \mathrm{H}$-pyran-2-yl)cinnamamide (9) possessed weak inhibitory activity against mouse platelet aggregation induced by AYPGKF-NH ${ }_{2}$, which is a gold agonist of protease-activated receptor 4.

\section{Conflict of interest}

Authors declare that there are no conflicts of interest associated with this work.

Acknowledgements This study was supported by the Southeast Asia Biodiversity Research Institute, Chinese Academy of Sciences (2015CASEABRIRG001 and Y4ZK111B01), the open foundation of Key Laboratory of Ethnomedicine (Minzu University of China), Ministry of Education (KLEM-KF2018Z01), and the International Partnership Program of Chinese Academy of Sciences (153631KYSB20160004).

Open Access This article is distributed under the terms of the Creative Commons Attribution 4.0 International License (http://creativeco mmons.org/licenses/by/4.0/), which permits unrestricted use, distribution, and reproduction in any medium, provided you give appropriate credit to the original author(s) and the source, provide a link to the Creative Commons license, and indicate if changes were made.

\section{References}

1. S. Vinay, K. Renuka, V. Palak, C.R. Harisha, P.K. Prajapati, J. Pharm. Sci. Innovat. 1, 62-66 (2012)

2. M. Kubo, R. Ishii, Y. Ishino, K. Harada, N. Matsui, M. Akagi, E. Kato, S. Hosoda, Y. Fukuyama, J. Nat. Prod. 76, 769-773 (2013)

3. J.W. Ahn, M.J. Ahn, O.P. Zee, E.J. Kim, S.G. Lee, H.J. Kim, I. Kubo, Phytochemistry 31, 3609-3612 (1992)

4. A. Banerji, D. Bandyopadhyay, M. Sarkar, A.K. Siddhanta, S.C. Pal, S. Ghosh, K. Abraham, J.N. Shoolery, Phytochemistry 24, 279-284 (1985)

5. R. Muharini, Z. Liu, W. Lin, P. Proksch, Tetrahedron Lett. 56, 2521-2525 (2015)

6. V.R.S. Rao, G. Suresh, K.S. Babu, S.S. Raju, M.V.P.S.V. Vardhan, S. Ramakrishna, J.M. Rao, Tetrahedron 67, 1885-1892 (2011)

7. H.S. Bodiwala, G. Singh, R. Singh, C.S. Dey, S.S. Sharma, K.K. Bhutani, I.P. Singh, J. Nat. Med. 61, 418-421 (2007)

8. H. Matsuda, K. Ninomiya, T. Morikawa, D. Yasuda, I. Yamaguchi, M. Yoshikawa, Bioorg. Med. Chem. 17, 7313-7323 (2009)

9. T. Morikawa, H. Matsuda, I. Yamaguchi, Y. Pongpiriyadacha, M. Yoshikawa, Planta Med. 70, 152-159 (2004)

10. M.Y. Xia, L. Wang, Y.H. Wang, Nat. Prod. Res. Dev. 28, 18761885 (2016)

11. D.D. Ding, Y.H. Wang, Y.H. Chen, R.Q. Mei, J. Yang, J.F. Luo, Y. Li, C.L. Long, Y. Kong, Phytochemistry 129, 36-44 (2016)

12. D.D. Zhang, J. Yang, J.F. Luo, X.N. Li, C.L. Long, Y.H. Wang, J. Asian Nat. Prod. Res. 20, 734-743 (2018)

13. M.Y. Xia, J. Yang, P.H. Zhang, X.N. Li, J.F. Luo, C.L. Long, Y.H. Wang, Nat. Prod. Bioprospect. 8, 419-430 (2018)

14. O. Okitsu, R. Suzuki, S. Kobayashi, J. Org. Chem. 66, 809-823 (2001)

15. T. Iwasaki, H. Horikawa, K. Matsumoto, M. Miyoshi, J. Org. Chem. 44, 1552-1554 (1979)

16. S.G. Pardeshi, D.E. Ward, J. Org. Chem. 73, 1071-1076 (2008)

17. S. Das, D. Addis, S. Zhou, K. Junge, M. Beller, J. Am. Chem. Soc. 132, 1770-1771 (2010)

18. L. Dai, C. Zang, S. Tian, W. Liu, S. Tan, Z. Cai, T. Ni, M. An, R. Li, Y. Gao, D. Zhang, Y. Jiang, Bioorg. Med. Chem. Lett. 25, 34-37 (2015)

19. G.G. Zapesochnaya, V.A. Kurkin, Chem. Nat. Compd. 18, 685688 (1982) 
20. T. Morikawa, I. Yamaguchi, H. Matsuda, M. Yoshikawa, Chem. Pharm. Bull. 57, 1292-1295 (2009)

21. C. Glacet, G. Troude, Bull. Soc. Chim. Fr., 292-296 (1964)

22. F. Kiuchi, N. Nakamura, Y. Tsuda, K. Kondo, H. Yoshimura, Chem. Pharm. Bull. 36, 2452-2465 (1988)

23. S.A. Lee, J.S. Hwang, X.H. Han, C. Lee, M.H. Lee, S.G. Choe, S.S. Hong, D. Lee, M.K. Lee, B.Y. Hwang, Arch. Pharm. Res. 31, 679 (2008)

24. S. Wu, C. Sun, S. Pei, Y. Lu, Y. Pan, J. Chromatogr. A 1040 , 193-204 (2004)

25. K. Li, W. Zhu, Q. Fu, Y. Ke, Y. Jin, X. Liang, Analyst 138, 33133320 (2013)

26. M.B. Tomas, T.C. Shiao, P.T. Nguyen, S. Bourgault, R. Roy, Pharm. Chem. J. 51, 995-1004 (2018)

27. I.K. Park, S.G. Lee, S.C. Shin, J.D. Park, Y.J. Ahn, J. Agric. Food Chem. 50, 1866-1870 (2002)

28. J.J. Chen, C.Y. Duh, H.Y. Huang, I.S. Chen, Helv. Chim. Acta 86, 2058-2064 (2003)

29. T. Narui, M. Takeuchi, R. Ishii, T. Ishida, T. Okuyama, Nat. Med. 49, 438-441 (1995)

30. H.J. Zhang, G.T. Tan, B.D. Santarsiero, A.D. Mesecar, N.V. Hung, N.M. Cuong, D. Doel Soejarto, J.M. Pezzuto, H.H.S. Fong, J. Nat. Prod. 66, 609-615 (2003)

31. K.O. Al-Footy, W.M. Alarif, M.S. Zubair, M.A. Ghandourah, M.M. Aly, Trop. J. Pharm. Res. 15, 1431-1438 (2016)

32. X.Y. Zhang, X.H. Cai, X.D. Luo, Chin. J. Nat. Med. 10, 36-39 (2012)
33. M. Ushiyama, T. Furuya, Phytochemistry 28, 3009-3013 (1989)

34. H. Otsuka, M. Yao, K. Kamada, Y. Takeda, Chem. Pharm. Bull. 43, 754-759 (1995)

35. J. O'Shea, C.S. Theile, R. Das, I.R. Babu, K. Charisse, M. Manoharan, M.A. Maier, I. Zlatev, Tetrahedron 74, 6182-6186 (2018)

36. T.R. Faruqi, E.J. Weiss, M.J. Shapiro, W. Huang, S.R. Coughlin, J. Biol. Chem. 275, 19728-19734 (2000)

37. M.D. Hollenberg, S. Mahmoud, S. Sabrina, H. Steeve, V. Nathalie, Br. J. Pharmacol. 143, 443-454 (2004)

38. S.L. French, J.R. Hamilton, Br. J. Pharmacol. 173, 2952-2965 (2016)

39. P.C. Wong, D. Seiffert, J.E. Bird, C.A. Watson, J.S. Bostwick, M. Giancarli, N. Allegretto, J. Hua, D. Harden, J. Guay, Sci. Transl. Med. 9, eaaf5294 (2017)

40. Y.H. Wang, J.H. Wang, H.P. He, H. Zhou, X.W. Yang, C.S. Li, X.J. Hao, J. Asian Nat. Prod. Res. 10, 25-31 (2008)

41. W. Yi, Q. Li, J. Shen, L. Ren, X. Liu, Q. Wang, S. He, Q. Wu, H. $\mathrm{Hu}$, X. Mao, L. Zhu, PloS ONE 9, e102394 (2014)

42. F. Maione, V. De Feo, E. Caiazzo, L. De Martino, C. Cicala, N. Mascolo, J. Ethnopharmacol. 155, 1236-1242 (2014)

43. W. Li, X. Tang, W. Yi, Q. Li, L. Ren, X. Liu, C. Chu, Y. Ozaki, J. Zhang, L. Zhu, PloS ONE 8, e85120 (2013)

44. D.P. Geraghty, K.D.K. Ahuja, J. Pittaway, C. Shing, G.A. Jacobson, N. Jager, S. Jurković, C. Narkowicz, C.I. Saunders, M. Ball, A. Pinkard, R.R. Vennavaram, M.J. Adams, J. Ethnopharmacol. 134, 97-103 (2011)

\section{Affiliations}

\section{Rong Tang ${ }^{1,3} \cdot$ Ya-Qiong Zhang ${ }^{2}$. Dong-Bao Hu ${ }^{4} \cdot$ Xue-Fei Yang ${ }^{1,5} \cdot$ Jun Yang ${ }^{1,5} \cdot$ Myint Myint San $^{6}$. Thaung Naing $\mathrm{Oo}^{6} \cdot$ Yi Kong $^{2} \cdot$ Yue-Hu Wang ${ }^{1,5}$}

1 Key Laboratory of Economic Plants and Biotechnology and the Yunnan Key Laboratory for Wild Plant Resources, Kunming Institute of Botany, Chinese Academy of Sciences, Kunming 650201, People's Republic of China

2 School of Life Science \& Technology, China Pharmaceutical University, Nanjing 210009, People's Republic of China

3 University of Chinese Academy of Sciences, Beijing 100049, People's Republic of China
4 School of Chemical Biology and Environment, Yuxi Normal University, Yuxi 653100, People's Republic of China

5 Southeast Asia Biodiversity Research Institute, Chinese Academy of Sciences, Yezin, Nay Pyi Taw 05282, Myanmar

6 Forest Research Institute, Yezin, Nay Pyi Taw 05282, Myanmar 